\title{
The Relationship Between a Statewide Preceptorship Program and Family Medicine Residency Selection
}

\author{
Victoria Stout Kubal, MS, John Zweifler, MD, MPH, Susan Hughes, MS, \\ Jo Marie Reilly, MD, and Sandra Newman, MPH
}

Objective: The purpose of this study was to investigate the extent to which participation in the California Academy of Family Physicians Foundation Family Medicine (FM) Preceptorship Program, as well as medical school, degree earned, gender, and match year predicted FM residency match.

Methods: Allopathic and osteopathic students who applied to the preceptorship program from 1996 to 2002 were followed until residency match. Chi-square $\left(\chi^{2}\right)$ analysis was used to compare preceptorship participants, nonparticipants (students who applied but did not complete the preceptorship), and nonapplicants (students who did not apply to the preceptorship) for FM match rates and to compare participants to nonparticipants for primary care match rates. FM match data for California schools from 1999 to 2005 were used to perform a logistic regression predicting FM match.

Results: Twenty-four percent of participants matched into FM residency programs whereas only 13\% of nonparticipants and 13\% of nonapplicants selected FM $\left(\chi^{2}=24.97 ; P<.001\right)$. There was not a statistically significant difference between the proportion of participants and nonparticipants who matched into primary care $\left(\chi^{2}=0.12 ; P=.73\right)$. Odds ratio results of logistic regression for participants compared with nonapplicants matching into FM was 2.7 (95\% CI, 2.0-3.6; $P<.001)$.

Conclusion: Preceptorship program participants were more likely than both nonparticipants and nonapplicants to select a FM residency. (J Am Board Fam Med 2010;23:67-74.)

Family physicians are important sources for primary care, yet the percentage of US allopathic and osteopathic graduates selecting a residency in family medicine (FM) has declined each year from 1998 to $2007 .^{1,2}$ In addition, more internal medicine and pediatric residents are selecting subspecialty residencies. ${ }^{1,3}$ According to the US Department of Health and Human Services Health Resources and Services Administration and the US

This article was externally peer reviewed.

Submitted 9 October 2008; revised 22 April 2009; accepted 27 April 2009.

From the Department of Family and Community Medicine, University of California, San Francisco, Fresno (VSK, JZ, SH); the Department of Family Medicine, University of Southern California-Keck School of Medicine, Los Angeles (JMR); and the California Academy of Family Physicians, San Francisco (SN), California.

Funding: Department of Family and Community Medicine at The University of California, San Francisco, Fresno, received partial funding from California Academy of Family Physicians to complete the data analysis.

Conflict of interest: none declared.

Corresponding author: John Zweifler, MD, MPH, Department of Family and Community Medicine, University of California, San Francisco, Fresno, 155 N. Fresno Street, Suite 326, Fresno, CA 93701 (E-mail: jzweifler@fresno. ucsf.edu).
Government Accountability Office, the supply of primary care physicians in general, and FM physicians in particular, may be inadequate to meet future needs. ${ }^{4,5}$

Programs designed to increase medical students' interest in primary care may help address this concern. One strategy to boost primary care selection among medical students is based on the premise that early primary care exposure improves the likelihood that students will choose a primary care specialty. To ensure consistent provision of this early exposure, the state of California mandated in 1999 that all allopathic and osteopathic students participate in a 4-week FM clinical core clerkship to be eligible for a physician's and surgeon's license. ${ }^{6}$ Before this mandate, in 1993, the California Academy of Family Physicians Foundation (CAFP-F) established a statewide 4-week preceptorship program for California allopathic and osteopathic students between their first and second years of medical school; the goal of this preceptorship was to increase exposure to a FM career. Other states, including Washington, Tennessee, Texas, Ohio, Minnesota, and Iowa, also offered primary 
care-related externship/fellowship/preceptorship programs through their medical schools. ${ }^{7-12} \mathrm{Al}-$ though each had a similar goal of influencing student specialty career choice, there was considerable variation in program design, duration, and financing.

Preceptorships offer students the experience of shadowing a preceptor, providing opportunities to learn aspects of medicine not available in traditional didactic and school-based environments. To both encourage participation and recognize the time commitment, most preceptorship programs, including the one through CAFP-F, provide stipends to students. ${ }^{7,9,11,13}$ Among the programs examined, the preceptorship duration varied from 3 weeks to 9 months, with a mode of 4 weeks. ${ }^{7-13}$ Most preceptorship programs noted above required a competitive application process; however, participation in the University of Iowa's program was compulsory and the University of Washington's program placed every student who applied. ${ }^{7-13}$

Aims of a successful FM preceptorship experience include educating the student participant about FM, generating interest in FM as a career, and ultimately increasing the number of medical students selecting FM residency programs. In a recent summary, authors concluded that medical student participation in FM-related special programs was one variable consistently associated with FM residency match rates. ${ }^{14}$ An analysis of 18 years of the month-long East Tennessee State University Appalachian Preceptorship Program indicated that $60 \%$ of participants selected FM and $82 \%$ matched into primary care (FM, internal medicine, and pediatrics). ${ }^{9}$ An evaluation of 9 years of Texas's Statewide Family Practice Preceptorship Program showed that $28 \%$ of participants in the 4 - and 8 -week preceptorship programs who graduated between 1992 and 2000 chose FM, whereas $16 \%$ of nonparticipants chose FM. ${ }^{11}$ Ohio State University found that $43 \%$ of participants (1993 to 1997 and 1999) in a paid, 6-week summer externship program selected FM. ${ }^{7}$ The University of Minnesota Medical School's Rural Physicians Associate Program reported that, from 1998 to 2004, 83\% of the 9-month primary care elective clerkship participants chose primary care (FM, internal medicine, and pediatrics). ${ }^{8}$ The University of Iowa's 3-week Family Practice Preceptorship Program reported that, from 1990 to1996, 29\% of those that com- pleted the program selected FM. ${ }^{10}$ Thirty-one percent of the University of Washington School of Medicine 1993 and 1994 graduates who participated in the 4-week Rural/Underserved Opportunities Program between 1989 and 1991 matched into FM and $63 \%$ matched into primary care (FM, internal medicine, pediatrics, and obstetrics/gynecology). ${ }^{13}$ These evaluations of the various programs demonstrate that preceptorships may have a positive effect on medical students' choice of residency programs. However, only University of Washington researchers gathered information about students' plans for future specialty choice at the time of medical school orientation and compared this to program participant and nonparticipant residency selection; they discovered that participation did not alter the likelihood of selecting a primary care residency. ${ }^{13}$

The CAFP-F has offered scholarships through the FM Preceptorship Program since 1993 to allow California allopathic and osteopathic students the opportunity to explore careers in FM by completing a 4-week, full-time preceptorship with a FM physician. In this study, we examined the CAFP-F FM Preceptorship Program's applicants from 1996 to 2002 to determine the influence of the CAFP-F Preceptorship Program on FM and primary care (FM, internal medicine, and pediatrics) residency match rates. We also compared CAFP-F program applicants to their California allopathic and osteopathic school colleagues for FM match rate from 1999 to 2005.

\section{Methods}

Data maintained by the CAFP-F for student applicants to their summer FM Preceptorship Program between 1996 and 2002 were supplied to the University of California, San Francisco, Fresno Department of Family and Community Medicine (UCSF Fresno FCM) without identifying information. UCSF Fresno FCM received partial funding from CAFP-F to complete the data analysis. The data about each student included medical school, out-of-state medical school status, specialty match, gender, acceptance status, and year applied. The Committee on Human Research, University of California, San Francisco's Institutional Review Board, approved this study as exempt. Descriptive statistics and data analyses were performed using SPSS software (version 16.0, SPSS Inc., Chicago, IL). 
All CAFP-F Preceptorship Program applicants submitted an application that included responses to essay questions that explored their interest in FM. Applications were reviewed and scored by at least 2 members of the CAFP-F Medical Student and Resident Affairs Committee. Reviewers were not blinded to any part of the application, which included both applicant name and allopathic/osteopathic school. Applicants with the highest average scores were invited to participate. Selection-process artifacts were neither provided to UCSF Fresno FCM nor considered in this analysis.

Preceptorship program applicants were classified into program participants and nonparticipants. The participant group included medical students who applied, were accepted, and completed the program. The nonparticipant group included 3 subgroups: (1) medical students who applied, were accepted, but did not attend the program; (2) medical students who applied, were placed on a waiting list, but did not attend the program; and (3) medical students who applied but were not accepted into the program. Medical school information (8 California allopathic schools and 2 osteopathic medical colleges) was used to categorize students as either MD or DO. Students' specialty matches were used to create dichotomous variables for both FM and primary care matches. Consistent with the $\mathrm{Na}$ tional Resident Matching Program primary care categories, as well as both the University of Minnesota and East Tennessee State University preceptorship programs, our primary care variable included matches into FM, pediatrics, and internal medicine. ${ }^{2,8,9}$

Although included in the descriptive statistics, 97 students without residency match information were excluded from the specialty match analyses. The CAFP-F Preceptorship Program was ostensibly limited to California medical school students, although 8 out-of-state medical students with California backgrounds were accepted into the program between 1996 and 1999. These 8 participants, as well as 61 other applicants from medical schools outside of California, were excluded from all analyses. One nonparticipant applicant, whose subgroup status was not known, was also excluded from all analyses.

The frequency of FM match from 1999 to 2005 by California school was obtained from peer-reviewed journals. ${ }^{15-21}$ For each year and California school, the number of students who did not apply to the preceptorship program but matched into FM was calculated by subtracting CAFP-F preceptorship applicants who matched into FM from the total number of students who matched into FM. Similarly, the number of students who neither applied to the preceptorship program nor matched into FM was calculated by subtracting the CAFP-F preceptorship applicants who did not match into FM from the total number of students who did not match into FM. From these calculations, a program participation variable was created to include a third group, nonapplicants, along with the participants and nonparticipants. Both participants and nonparticipants had applied to the program; nonapplicants had never applied to the program.

The significance level for all statistical analyses was set at $5 \%$. Pearson chi-square $\left(\chi^{2}\right)$ tests were used to compare differences among the following categorical variables: FM and non-FM match as related to participants, nonparticipants, and nonapplicants; primary care and non-primary care match as related to participants and nonparticipants; and students with and without available residency match information. Logistic regression was used to examine the relationship between FM match and CAFP-F program participation while controlling for medical school and match year.

\section{Results}

Five hundred eighty-two medical students applied to the CAFP-F FM Preceptorship Program between 1996 and 2002. Demographics on these applicants are presented in Table 1 . The yearly number of applicants varied, with a high of 104 in 2000 and a low of 56 in 2002. The University of California, Irvine, consistently produced the most applicants and participants. Osteopathic students from Touro University first applied and were accepted into the CAFP-F preceptorship program in 2002. An average of 45 students per year participated in the preceptorship program, $55 \%$ of whom were women.

Of the 582 participants and nonparticipants, there was no statistically significant difference with regard to gender $\left(\chi^{2}=0.56 ; P=.45 ;\right.$ see Table 1$)$ or the type of degree earned $\left(\chi^{2}=0.13 ; P=.72\right.$; see Table 1$)$. There were statistically significant differences between the proportion of participants and nonparticipants with regard to medical school $\left(\chi^{2}=42.97 ; P<.001 ;\right.$ see Table 1$)$; year applied $\left(\chi^{2}\right.$ 
Table 1. Applicants to California Academy of Family Physicians Foundation Family Medicine Preceptorship Program from 1996 to 2002

\begin{tabular}{|c|c|c|c|c|}
\hline Variables & $\begin{array}{l}\text { Participants* } \\
\text { (n [\%]) }\end{array}$ & $\begin{array}{l}\text { Nonparticipants }{ }^{\dagger} \\
(\mathrm{n}[\%])\end{array}$ & Total (n) & $P$ \\
\hline School & & & & $<.001^{\ddagger}$ \\
\hline Loma Linda University & $18(37)$ & $31(63)$ & 49 & \\
\hline Stanford University & $29(67)$ & $14(33)$ & 43 & \\
\hline Touro University & $2(100)$ & $0(0)$ & 2 & \\
\hline University of California, Davis & $19(76)$ & $6(24)$ & 25 & \\
\hline University of California, Irvine & $88(67)$ & $43(33)$ & 131 & \\
\hline $\begin{array}{l}\text { University of California, Los } \\
\text { Angeles }\end{array}$ & $16(28)$ & $42(72)$ & 58 & \\
\hline University of California, San Diego & $22(54)$ & $19(46)$ & 41 & \\
\hline $\begin{array}{l}\text { University of California, San } \\
\text { Francisco }\end{array}$ & $38(45)$ & $46(55)$ & 84 & \\
\hline University of Southern California & $55(59)$ & $38(41)$ & 93 & \\
\hline Western University & $31(55)$ & $25(45)$ & 56 & \\
\hline Degree & & & & .72 \\
\hline $\mathrm{DO}$ & $33(57)$ & $25(43)$ & 58 & \\
\hline MD & $285(54)$ & $239(46)$ & 524 & \\
\hline Gender & & & & $.45^{\S}$ \\
\hline Female & $176(58)$ & $130(42)$ & 306 & \\
\hline Male & $132(54)$ & $111(46)$ & 243 & \\
\hline Unknown & $10(30)$ & $23(70)$ & 33 & \\
\hline Year & & & & $<.001$ \\
\hline 1996 & $37(47)$ & $41(53)$ & 78 & \\
\hline 1997 & $43(47)$ & $49(53)$ & 92 & \\
\hline 1998 & $46(45)$ & $57(55)$ & 103 & \\
\hline 1999 & $52(63)$ & $31(37)$ & 83 & \\
\hline 2000 & $51(49)$ & $53(51)$ & 104 & \\
\hline 2001 & $44(67)$ & $22(33)$ & 66 & \\
\hline 2002 & $45(80)$ & $11(20)$ & 56 & \\
\hline Residency match & & & & $<.001$ \\
\hline Known & $281(88)$ & $204(77)$ & 485 & \\
\hline Unknown & $37(12)$ & $60(23)$ & 97 & \\
\hline
\end{tabular}

*Participants attended the preceptorship program.

${ }^{\dagger}$ Nonparticipants applied to the preceptorship program but did not attend.

${ }^{\ddagger} \chi^{2}$ analysis did not include the 1 year of data from Touro University.

${ }^{\$} \chi^{2}$ analysis did not include unknown gender.

$=30.35 ; P<.001$; see Table 1$)$; and whether or not CAFP-F was missing specialty match data $\left(\chi^{2}=\right.$ 12.78; $P<.001$; see Table 1 ).

Four hundred eighty-five of the 582 applicants had known specialty matches; residency match information was missing for 37 (11.6\%) program participants and $60(22.7 \%)$ nonparticipants. There was not a statistically significant difference between applicants with and without match information in regard to gender $\left(\chi^{2}=0.68 ; P=.41\right)$. To varying levels of statistical significance, there were differences between applicants with and without match information with regard to application year $\left(\chi^{2}=\right.$
$16.41 ; P=.01)$; degree earned $\left(\chi^{2}=7.42 ; P=.01\right)$; and medical school $\left(\chi^{2}=70.09 ; P<.001\right)$.

CAFP-F Preceptorship participants from 1996 to 2002 matched into residency programs between 1999 and 2005. Of the 485 applicants with known specialty matches, 281 were program participants and 204 were nonparticipants. Sixty-seven (24\%) participants selected FM residencies compared with 26 nonparticipants $\left(13 \% ; \chi^{2}=9.39 ; P=.002\right.$; see Figure 1 and Table 2). The 26 nonparticipants who matched into FM residencies included 5 of 39 medical students (13\%) who applied and were accepted but did not attend the preceptorship pro- 
Figure 1. California Academy of Family Physicians Foundation Family Medicine Preceptorship Program applicant match rates (1999 to 2005) for family medicine and primary care residencies.

${ }^{*}$ Match rates into family medicine were statistically significant $\left(\chi^{2}=24.97 ; P<.001\right) .{ }^{\dagger}$ Match rates into primary care were not statistically significant $\left(\chi^{2}=0.12 ; P=.73\right)$. ${ }^{\ddagger}$ Participants attended the preceptorship program. ${ }^{\$}$ Nonparticipants applied to the preceptorship program, but did not attend. "Nonapplicants did not apply to the preceptorship program.

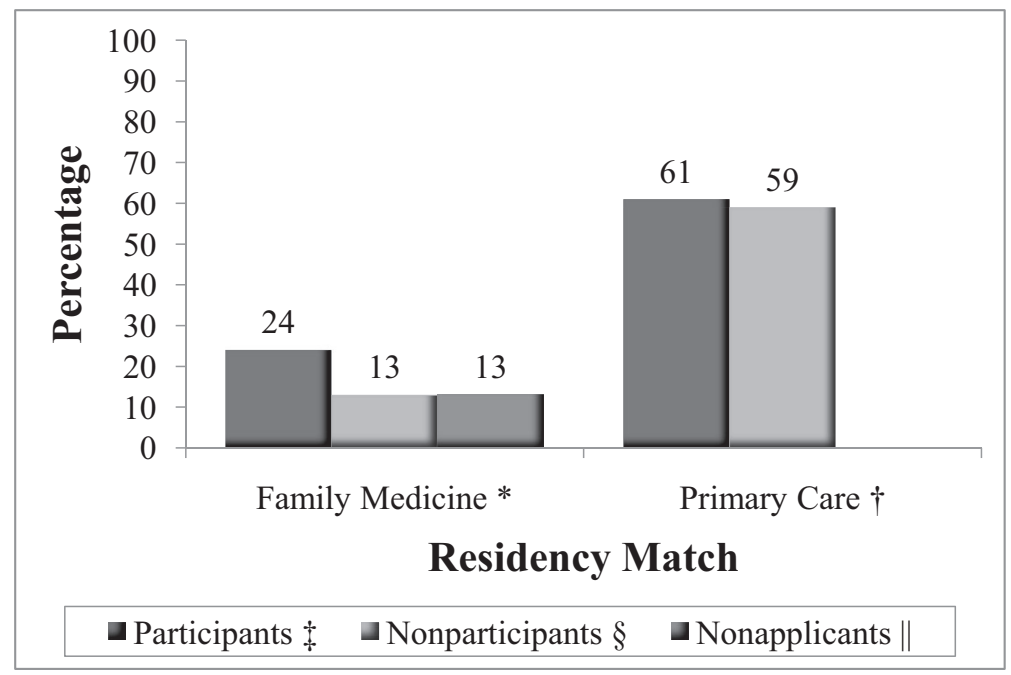

gram as well as 21 of 143 medical students (15\%) who applied but were not accepted (see Table 2). None of the 22 medical students who applied but were wait-listed and did not participate matched into FM.

The proportion of osteopathic student applicants who selected FM (46\%) was greater than the proportion of allopathic student applicants $(17 \%$; $\left.\chi^{2}=21.33 ; P<.001\right)$. In a separate analysis, there was not a statistically significant difference between the proportion of osteopathic student $(63 \%)$ and allopathic student $(60 \%)$ applicants who matched into primary care $\left(\chi^{2}=0.19 ; P=.66\right)$. Nor was there a statistically significant difference between the gender of students who matched into FM $(21 \%$ of women, $18 \%$ of men; $\chi^{2}=0.54 ; P=.46$ ) or into primary care $\left(62 \%\right.$ of women, $57 \%$ of men; $\chi^{2}=$ $1.58 ; P=.21)$.

One hundred seventy-one participants (61\%) matched into primary care residencies, compared with 121 nonparticipants $\left(59 \% ; \chi^{2}=0.12 ; P=.73\right.$; see Figure 1). The 121 nonparticipants who selected primary care residencies included 20 of 39 medical students $(51 \%)$ who applied and were accepted but did not attend the program; 10 of 22 medical students (45\%) who applied but were waitlisted and did not participate; and 91 of 143 medical students (64\%) who applied but were not accepted.
From 1999 to 2005 , a total of 8773 allopathic and osteopathic students graduated from California schools. In a separate $\chi^{2}$ analysis of all 1999 to 2005 California graduates, comprised of 281 CAFP-F program participants, 204 nonparticipants, and 8288 nonapplicants, 1207 (24\% of program participants, $13 \%$ of nonparticipants, and $13 \%$ of nonapplicants) matched into FM residency programs $\left(\chi^{2}=24.97 ; P<.001\right.$; see Table 2). Controlling for match year and medical school, participants were 2.7 times more likely than nonapplicants to match into FM (95\% CI, 2.0-3.6; $P<.001)$. The odds ratio for nonparticipants compared with nonapplicants matching into FM was not statistically significant (odds ratio, 1.2; 95\% CI, 0.8-1.8; $P=.42$ ).

\section{Discussion}

In this analysis we examined CAFP-F FM Preceptorship Program applicants from 1996 to 2002. We found that preceptorship participants were significantly more likely to match into FM residencies than were applicants who did not participate in the program. The association between preceptorship participation and matching into a FM residency persisted in logistic regression models that accounted for medical school and year of graduation. There was not a statistically significant difference between the propor- 
Table 2. California match rates (1999-2005) for family medicine residencies across California Academy of Family Physicians Foundation Family Medicine Preceptorship Program application and participation categories

\begin{tabular}{|c|c|c|c|}
\hline \multirow[b]{2}{*}{ Acceptance Status } & \multicolumn{2}{|c|}{$\begin{array}{l}\text { Residency Selection } \\
\text { (n [\%]) }\end{array}$} & \multirow[b]{2}{*}{ Total (n) } \\
\hline & Family Medicine & Non-Family Medicine & \\
\hline \multicolumn{4}{|l|}{ Participants } \\
\hline Total program attendees & $67(24)$ & $214(76)$ & 281 \\
\hline \multicolumn{4}{|l|}{ Nonparticipants } \\
\hline Total nonparticipants & $26(13)$ & $178(87)$ & 204 \\
\hline Accepted but did not attend & $5(13)$ & $34(87)$ & 39 \\
\hline Alternate and did not attend & $0(0)$ & $22(100)$ & 22 \\
\hline Not accepted/did not attend & $21(15)$ & $122(85)$ & 143 \\
\hline \multicolumn{4}{|l|}{ Nonapplicants } \\
\hline Total did not apply & $1114(13)$ & $7174(87)$ & 8288 \\
\hline Total California graduates & $1207(14)$ & $7566(86)$ & 8773 \\
\hline
\end{tabular}

tion of participants and nonparticipants who matched into a primary care specialty.

Our findings must be considered within their geographic and temporal context. The CAFP-F FM Preceptorship Program attracted students from each of the allopathic and osteopathic schools in California. This suggests the CAFP-F FM Preceptorship Program had broad appeal and our findings reflected the diversity of students and preferences found at campuses throughout California. During the 1999 to 2005 time frame, when CAFP-F FM preceptorship participants graduated, California medical school graduates as a whole selected FM residencies at rates very close to the national average—slightly above when osteopathic schools are included and slightly below when osteopathic schools are excluded. ${ }^{15-21}$

When comparing FM match rates for CAFP-F FM preceptorship participants to those from other preceptorship programs, the percentage of CAFP-F FM preceptorship participants who entered FM residencies (24\%) was lower; although other programs included data before 1998, before the number of US medical school graduates selecting FM residencies began declining. ${ }^{2,7,9-11,13}$ Further, there are regional differences in match rates across the country. These differences may account for some of the variation in FM match rates between preceptorship programs reported in the literature. Between 1999 and 2005, the California allopathic student match rate was below the national average for 2 of the years; of the other states with preceptorship programs discussed in this arti- cle, only Tennessee was below the national average more often than California., ${ }^{9}, 21$

Programmatic differences may also impact the FM match rates of preceptorship participants. For example, although the CAFP-F FM preceptorship program was 4 weeks in length, others lasted from a low of 3 weeks up to a high of 9 months. ${ }^{7-13}$ Yet there was not a consistent relationship between preceptorship duration and the percentage of students entering FM residencies across examined programs. ${ }^{7-13}$ The FM match rates for the California (24\%) and Texas (28\%) preceptorship programs, the only 2 American Academy of Family Physicians state chapter-sponsored preceptorship programs reported in the literature, were lower than those aligned with specific medical schools. ${ }^{7-13,22}$ The process for recruiting and selecting students to participate in the preceptorship program may also influence subsequent match rates. Given their proximity to students, programs organized by medical schools may be better able to identify and target students likely to enter FM residencies and ultimately may be better positioned to send participants into FM residency.

\section{Limitations}

This study had several limitations. The study was not randomized, and student interest in FM and primary care was not quantified before students applied to the preceptorship program or soon after participation. Additional factors associated with a higher likelihood of selecting FM (ie, older age, Hispanic ethnicity, rural background, etc) were not included among the 
variables provided by CAFP-F. ${ }^{14}$ We did not differentiate between those who entered an internal medicine residency program and those who entered residency but later became certified in a subspecialty, which would have probably lessened the number of true matches into primary care; however, it is unclear how this would proportionally affect the categories of participants and nonparticipants.

Some data were missing for both participants and nonparticipants. The difference in the proportion of match data obtained from participants $(11.6 \%)$ and nonparticipants $(22.7 \%)$ may be because CAFP-F provided incentives for participants to respond and remain in contact through delaying the full payment of their scholarship until after submission of the survey taken after the preceptorship; however, this did not guarantee that the survey was completed in full. The CAFP-F data collection process may also have been biased because students who later supplied updated information to CAFP-F may be more likely to enter FM. It is possible that information collected externally (not directly from the student) may not have been accurate, but the direction of this potential bias cannot be determined.

Compared with those students whose residency match information was known, the proportion of students with missing match data were greater among nonparticipants than participants, greater among osteopathic students than allopathic students, and greatest in 2001. Nonparticipants were less likely to select FM than participants; thus, including the missing nonparticipant match information could potentially decrease the strength of the association. Osteopathic student applicants were more likely to select FM; thus, including the missing osteopathic match information could potentially increase the strength of the association. In 2001, there were fewer applicants matching into FM than in any other year studied (data not shown); thus the outcome direction of including this missing match information is unknown.

Methods of recruitment and selection may have been biased. There was not an equal number of participants from each California school (see Table 1). CAFP-F relied on the American Academy of Family Physicians Family Medicine Interest Group leaders and predoctoral coordinators at each school to assist in the recruitment process, which could have lead to variability in recruitment intensity across California schools and may have affected the number of applicants from each school. The schools' emphasis on FM and the availability of competing preceptorship opportunities may also have affected students' decisions to apply or not apply to the CAFP-F preceptorship program. Data about the selection process itself was not available; however, because the criteria included students' interest in FM, the process of selecting applicants was biased in favor of those likely to continue in a FM residency program.

Finally, our study was limited by the selection bias of students who initially signaled their interest in FM and primary care by applying to the preceptorship program in the first place; we did not, however, find significant differences between FM match rates of nonparticipants and nonapplicants. If student selection bias had played a major role in our findings, we would expect those who applied to the program, even if they did not participate in the program, to have selected FM at higher rates than nonapplicants. This was not the case. We also did not see any statistical difference between participants and nonparticipants in selecting a primary care residency. These findings suggest that there was a relationship between participating in the program and selecting FM.

\section{Conclusions}

Other avenues of investigation are suggested by this analysis. Could the selection process be modified so that these limited preceptorship positions are given to applicants who are most likely to be swayed to enter FM and primary care residencies? Could not being accepted have dissuaded some applicants from selecting FM? How many program participants used this experience to help them decide that FM was not the best choice? Is there a relationship between preceptorship programs and later participation in FM leadership positions? Does the investment in time and energy justify the modest but significant increase in participants selecting FM residencies? Further study is needed to answer these questions.

FM needs unique, innovative, and stimulating programs to generate interest among allopathic and osteopathic students. The results of the logistic regression and $\chi^{2}$ analyses indicate that participants in the CAFP-F FM Preceptorship Program were significantly more likely than both nonparticipants and nonapplicants to select FM residencies. We should continue to offer and to assess preceptorship programs with an eye to determining the most efficient models for encouraging medical students 
to enter FM residencies, thereby ensuring an adequate supply of FM physicians in the future.

\section{References}

1. Newton DA, Grayson MS. Trends in career choice by US medical school graduates. JAMA 2003;290: $1179-82$.

2. American Academy of Family Physicians Division of Medical Education. 2007 match summary and analysis. Available at http://www.aafp.org/online/en/ home/residents/match/summary.html. Accessed 3 July 2007.

3. Garibaldi RA, Popkave C, Bylsma W. Career plans for trainees in internal medicine. Acad Med 2005;80: 507-12.

4. U.S. Department of Health and Human Services, Health Resources and Services Administration. Physician supply and demand: projections to 2020. Available at http://bhpr.hrsa.gov/healthworkforce/ reports/physiciansupplydemand/default.htm. Accessed 15 January 2009.

5. US Government Accountability Office. Primary care professionals: recent supply trends, projections, and valuation of services. Available at http://www. gao.gov/products/GAO-08-472T. Accessed 6 January 2009.

6. Medical Board of California. Laws Relating to Physicians and Surgeons, Doctors of Podiatric Medicine, Registered Dispensing Opticians, Research Psychoanalysts, Medical Assistants, Perfusionists, Dietitians, and Licensed Midwives. Charlottesville, VA: Michie; 2006.

7. Cronau H, Haines DJ. Medical student summer externship program: increasing the number matching in family practice. Med Educ Online. 2004;9:1-5.

8. Halaas GW. The Rural Physician Associate Program: successful outcomes in primary care and rural practice. Rural Remote Health 2005;5:453.

9. Lang F, Ferguson KP, Bennard B, Zahorik P, Sliger C. The Appalachian Preceptorship: over two decades of an integrated clinical-classroom experience of rural medicine and Appalachian culture. Acad Med 2005;80:715-6.

10. Levy BT, Hartz A, Merchant ML, Schroeder BT. Quality of a family medicine preceptorship is significantly associated with matching into family practice. Fam Med 2001;33:683-90.
11. Nieman LZ, Foxhall LE, Chuang AZ, Cheng L, Prager TC. Evaluating the Texas Statewide Family Practice Preceptorship Program, 1992-2000. Acad Med 2004;79:62-8.

12. Ramsey PG, Coombs JB, Hunt DD, Marshall SG, Wenrich MD. From concept to culture: the WWAMI program at the University of Washington School of Medicine. Acad Med 2001;76:765-75.

13. Dobie SA, Carline JD, Laskowski MB. An early preceptorship and medical students' beliefs, values, and career choices. Adv Health Sci Educ Theory Pract 1997;2:35-47.

14. Campos-Outcalt D, Senf J, Pugno PA, McGaha AL. Family medicine specialty selection: a proposed research agenda. Fam Med 2007;39:585-9.

15. McPherson DS, Schmittling GT, Pugno PA, Kahn NB. Entry of US medical school graduates into family medicine residencies: 2001-2002 and 3-year summary. Fam Med 2002;34:575-83.

16. McPherson DS, Schmittling GT, Pugno PA, Kahn NB. Entry of US medical school graduates into family medicine residencies: 2002-2003 and 3-year summary. Fam Med 2003;35:555-63.

17. McPherson DS, Schmittling GT, Pugno PA, Kahn NB. Entry of US medical school graduates into family medicine residencies: 2003-2004 and 3-year summary. Fam Med 2004;36:553-61.

18. Pugno P, Schmittling GT, McPherson DS, Kahn NB. Entry of US medical school graduates into family medicine residencies: 1999-2000 and 3-year summary. Fam Med 2000;32:534-42.

19. Pugno P, Schmittling GT, McPherson DS, Kahn NB. Entry of US medical school graduates into family medicine residencies: 2000-2001 and 3-year summary. Fam Med 2001;33:585-93.

20. Pugno PA, Schmittling GT, Kahn NB. Entry of US medical school graduates into family medicine residencies: 2004-2005 and 3-year summary. Fam Med 2005;37:546-54.

21. Pugno PA, Schmittling GT, McGhana AL, Kahn NB. Entry of US medical school graduates into family medicine residencies: 2005-2006 and 3-year summary. Fam Med 2006;38:626-36.

22. Texas Statewide Family Practice Preceptorship Program: about the program. Available at https:// www2.mdanderson.org/sapp/preceptorship/about. aspx. Accessed 25 March 2009. 